Review

\title{
Insights into the role of ERp57 in cancer
}

\author{
Danyang Song1, Hao $\mathrm{Liu}^{2}$, Jian $\mathrm{Wu}^{2}$, Xiaoliang Gao ${ }^{2}$, Jianyu Hao ${ }^{\circledR}$, Daiming Fan ${ }^{1,2}$ \\ 1. Department of Gastroenterology, Beijing Chaoyang Hospital, Capital Medical University, Beijing 100020, China. \\ 2. State key Laboratory of Cancer Biology, National Clinical Research Center for Digestive Diseases and Xijing Hospital of Digestive Diseases, Air Force \\ Military Medical University, Xi'an 710032, China. \\ $\triangle$ Corresponding authors: Daiming Fan, email: daimingfan@fmmu.edu.cn; phone number: +86-029-84775507; Jianyu Hao, email: haojianyu@ccmu.edu.cn.
}

(1) The author(s). This is an open access article distributed under the terms of the Creative Commons Attribution License (https://creativecommons.org/licenses/by/4.0/). See http://ivyspring.com/terms for full terms and conditions.

Received: 2020.05.29; Accepted: 2021.02.04; Published: 2021.03.01

\begin{abstract}
Endoplasmic reticulum resident protein 57 (ERp57) has a molecular weight of $57 \mathrm{kDa}$, belongs to the protein disulfide-isomerase (PDI) family, and is primarily located in the endoplasmic reticulum (ER). ERp57 functions in the quality control of nascent synthesized glycoproteins, participates in major histocompatibility complex (MHC) class I molecule assembly, regulates immune responses, maintains immunogenic cell death (ICD), regulates the unfolded protein response (UPR), functions as a 1,25-dihydroxy vitamin $\mathrm{D}_{3}\left(1,25(\mathrm{OH})_{2} \mathrm{D}_{3}\right)$ receptor, regulates the NF-KB and STAT3 pathways, and participates in DNA repair processes and cytoskeletal remodeling. Recent studies have reported ERp57 overexpression in various human cancers, and altered expression and aberrant functionality of ERp57 are associated with cancer growth and progression and changes in the chemosensitivity of cancers. ERp57 may become a potential biomarker and therapeutic target to combat cancer development and chemoresistance. Here, we summarize the available knowledge of the role of ERp57 in cancer and the underlying mechanisms.
\end{abstract}

Key words: ERp57/PDIA3, cancer, immune response, immunogenic cell death, unfolded protein response, DNA repair.

\section{Introduction}

With cancer incidence and mortality rates increasing rapidly, cancer has become a global problem and is expected to become the leading cause of death worldwide in the 21st century according to the Global Cancer Statistics 2018 report [1]. To ease the burden of cancer, current research is focusing largely on molecular preventive trials, which are regarded as the priority study type; biomarkers are key determinants of molecular prevention that allow us to evaluate the natural history of cancer as well as the efficacy and toxicity of an agent [2]. Recent research regarding the expression of endoplasmic reticulum resident protein 57 (ERp57) in tumors revealed that ERp57 expression is upregulated in various cancers and participates in cancer initiation, progression and chemosensitivity [3-5]. Some evidence suggests that ERp57 can serve as a potential molecular marker and therapeutic target of cancer [6]. ERp57 has a molecular weight of $57 \mathrm{kDa}$ and belongs to the protein disulfide-isomerase (PDI) family; it is also referred to as protein disulfide-isomerase A3 (PDIA3), glucose regulatory protein 58 (GRP58) or ER60 protease and is mainly located in the endoplasmic reticulum (ER), with lower amounts in the cytoplasm and nucleus $[7,8]$. Numerous studies have demonstrated that ERp57 is associated with multiple diseases, such as Alzheimer's disease [9], heart failure [10], thrombus formation [11, 12], neurodegenerative disease and cancer [13]. This review summarizes current knowledge relating to the key elements and mechanisms of ERp57 in various tumor functions, such as the regulation of $\mathrm{T}$ cell-mediated immune responses, regulation of immunogenic cell death, regulation of the unfolded protein response (UPR), regulation of DNA repair signaling and regulation of membrane-initiated signaling pathways. 


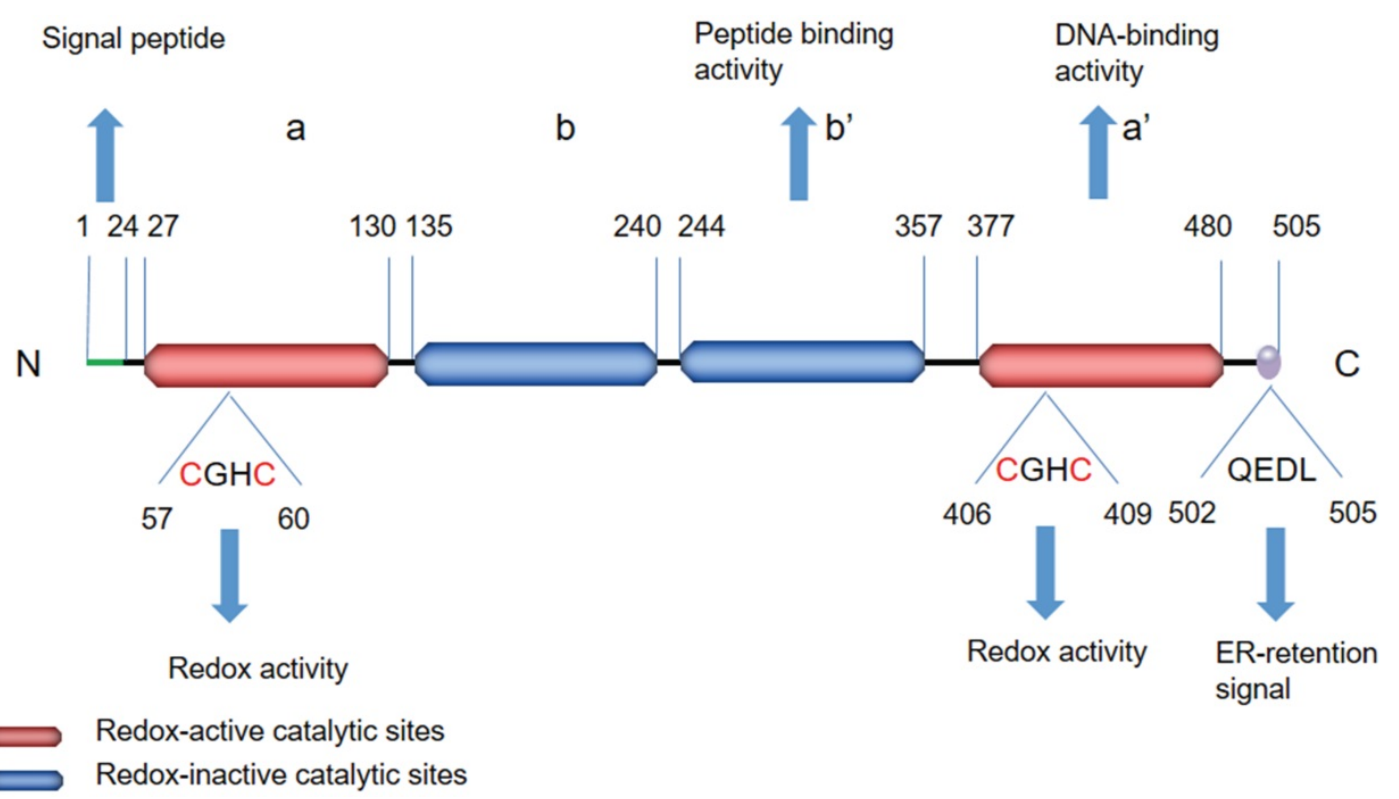

Figure 1. Schematic representation of the structural features of ERp57. ERp57 has four thioredoxin-like site domains-termed a, b, b', and a'-and an acidic C-terminal tail. The $\mathrm{C}$-terminus contains a QEDL sequence that serves as an ER retention signal. The redox-active catalytic sites in the a and a' domains are shown in red, while the redox-inactive catalytic sites in the $b$ and $b^{\prime}$ domains are shown in blue. The redox-active catalytic sites involve a CGHC sequence. The a' domain has DNA-binding activity, and the b' domain has peptide-binding activity.

\begin{tabular}{|c|c|c|c|c|}
\hline 10 & 20 & 30 & 40 & 50 \\
\hline \multicolumn{5}{|c|}{ ALFP GVALLLAAAR LAAASDVLEL TDDNFESRIS DTGSAGLMLV } \\
\hline 60 & 70 & 80 & 90 & 100 \\
\hline \multicolumn{5}{|c|}{ EFFAPWCGHC KRLAPEYEAAATRLKGIVPL AKVDCTANTN TCNKYGVSGY } \\
\hline 110 & 120 & 130 & 140 & 150 \\
\hline \multicolumn{5}{|c|}{ PTLKIFRDGE EAGAYDGPRT ADGIVSHLKK QAGPASVPLR TEEEFKKFIS } \\
\hline 160 & 170 & 180 & 190 & 200 \\
\hline \multicolumn{5}{|c|}{ DKDASIVGFF DDSFSEAHSE FLKAASNLRD NYRFAHTNVE SLVNEYDDNG } \\
\hline 210 & 220 & 230 & 240 & 250 \\
\hline \multicolumn{5}{|c|}{ EGIILFRPSH LTNKFEDKTV AYTEQKMTSG KIKKFIQENI FGICPHMTED } \\
\hline 260 & 270 & 280 & 290 & 300 \\
\hline \multicolumn{5}{|c|}{ NKDLIQGKDL LIAYYDVDYE KNAKGSNYWR NRVMMVAKKF LDAGHKLNFA } \\
\hline 310 & 320 & 330 & 340 & 350 \\
\hline \multicolumn{5}{|c|}{ VASRKTFSHE LSDFGLESTA GEIPVVAIRT AKC } \\
\hline 360 & 370 & 380 & 390 & 400 \\
\hline \multicolumn{5}{|c|}{ RFLQDYFDGN LKRYLKSEPI PESNDGPVKV VVAENFDEIV NNENKDVLIE } \\
\hline 410 & 420 & 430 & 440 & 450 \\
\hline $\mathrm{GH}$ & KELC & & & EVRGF \\
\hline 460 & 470 & 480 & 490 & 500 \\
\hline
\end{tabular}

AQEDL

Figure 2. The amino acid sequence of ERp57 and the functional domains. ERp57 has a total of 505 amino acids including four thioredoxin-like site domains, two redox-active catalytic sites, two redox-inactive catalytic sites, and a C-terminal ER retention signal. The redox-active catalytic sites are shown with a red background, while the redox-inactive catalytic sites are shown with a blue background. The C-terminus contains a QEDL sequence shown in purple.

\section{Structure}

The PDI family includes more than 20 members that catalyze cysteine-based redox reactions and play critical roles in productive protein folding [14, 15]. ERp57 is a highly conserved protein consisting of four thioredoxin-like site domains - termed a, b, $b^{\prime}$, and $\mathrm{a}^{\prime}$ - and an acidic C-terminal tail (Figure 1). Domains $a$ and $a^{\prime}$ contain the redox active site, whereas domains $b$ and $b^{\prime}$ are redox inactive. The two thioredoxin-like active domains a and a' each contain a Cys-Gly-His-Cys (CGHC) sequence (Figure 2), and the redox activity of the two domains is provided by the two cysteine residues of the CGHC motif $[16,17]$. ERp57 exerts reduction, oxidation and disulfide isomerization effects in the ER through thioredoxin-like domains $[16,17]$. The $b^{\prime}$ domain contains a ligand-binding site and exhibits 
high-affinity binding with protein substrates, including both small and large peptide ligands. The $b^{\prime}$ domain is involved in simple isomerization reactions and directs noncovalent binding to substrates to destabilize the conformation of partially folded species [18]. The C-terminus contains a $\mathrm{COOH}-$ terminal Gln-Glu-Asp-Leu (QEDL) tetrapeptide that serves as an ER retention signal and acts in cooperation with other amino acid residues [13, 19-21]. ERp57 has two general functions: ERp57 binds to double-stranded DNA via recognition of a particular scaffold/matrix-associated region sequence and recruits proteins that localize to the nuclear matrix [22]. The DNA-binding properties are associated with the C-terminal region a' domain [23, 24]. The affinity of ERp57 for DNA fragments is strongly dependent on the redox state of the two thioredoxin-like sites (i.e., the oxidation of its cysteines) [23, 25]. There is a nuclear location sequence in close proximity to its C-terminus; thus, ERp57 can translocate to the nucleus from the cytosol to regulate the transcription of target genes [26, 27]. ERp57 exhibits proteolytic activity, degrades other ER proteins and is regulated by acidic phospholipids, including phosphoinositides [19].

\section{Clinical implications of ERp57 in cancer}

Recent research from in vitro analyses and clinical trials support that ERp57 is overexpressed in a variety of cancers. ERp57 expression is significantly different between tumor tissues and normal tissues $(P$ $<0.05$ ) in a wide variety of cancers, including stomach adenocarcinoma, colon adenocarcinoma, liver hepatocellular carcinoma (HCC), breast invasive carcinoma, and prostate adenocarcinoma, as shown in Figure 3. UALCAN analysis (http://ualcan.path. uab.edu/analysis.html) [28] was applied to demonstrate the difference in the mRNA expression of ERp57 between paratumor samples and tumor samples of The Cancer Genome Atlas (TCGA) genomics dataset.

Some studies have demonstrated that ERp57 is a primary cellular target that inhibits cancer cell proliferation [29]. ERp57 expression significantly differs among HCC patients, at-risk patients and healthy individuals, thereby potentially serving as a biomarker for the early diagnosis of HCC [6]. Evidence suggests that ERp57 is overexpressed in HCC, colorectal cancer [30] and breast cancer [31, 32] and participates in tumorigenesis and the progression of cancer [3, 4]. ERp57 expression is associated with the metastatic capacity of cancer cells. ERp57 is overexpressed in $73 \%$ of cervical cancers, especially in adenocarcinoma, and high expression indicates poor overall survival and high recurrence-free survival rates in adenocarcinoma patients [33, 34]. In vitro, knockdown of ERp57 in HeLa cells inhibits cancer invasiveness and metastasis [33, 34]. ERp57 levels are also related to the malignant stages of prostate cancer [35]. Similarly, high levels of ERp57 in uveal melanoma may indicate that the tumor will metastasize [36]. However, ERp57 exerts the opposite effect on gastric cancer progression; its expression is significantly decreased in gastric cancer and metastases, and low levels of ERp57 are correlated with an increased depth of tumor invasion and advanced disease stage [37]. The results of retrospective analysis have shown that high expression indicates favorable overall survival in gastric cancer patients [38]. ERp57 is also related to gastric cancer treatment. Clinical trials have shown that ERp57 levels in the serum of patients with gastric cancer are decreased significantly after surgical treatment [39]. Taken together, these studies demonstrate that ERp57 is associated with tumor initiation and development; however, the implication of ERp57 in cancer is still debated. ERp57 may exert different functions depending on developmental and tissue-specific factors, but it is yet to be understood in detail. Thus, further study to uncover the mechanisms by which ERp57 modulates tumor tumorigenesis and progression is required. Here, we summarize the current research on the biological functions and mechanisms of ERp57 in cancer.

\section{Biological functions of ERp57 in cancer}

\section{Regulation of $\mathrm{T}$ cell-mediated immune responses}

Calnexin (CNX) and calreticulin (CRT) predominantly act as lectins that specifically interact with nascently synthesized glycoproteins in the ER, and ERp57 forms complexes with these proteins to accomplish efficient folding and proper formation of intramolecular disulfide bonds in glycoproteins [40, 41]. ERp57 binding to substrates is dependent on CNX and CRT and is inhibited by the glucosidase inhibitor castanospermine (CST), an inhibitor of glucosidases I and II [42]. ERp57 mediates disulfide bond formation with heavy chains and complexes with CNX [43] to participate in major histocompatibly complex (MHC) class I molecule assembly [44]. ERp57 is indispensable for antigen processing and presentation, contributing to the activity of $\mathrm{T}$ cell-mediated immune responses. ERp57 is a component of the antigen processing complex that binds to nascently synthesized glycoproteins and facilitates peptide transport from the cytosol into the ER; afterwards, peptides bind to newly synthesized MHC class I molecules to form the MHC class I peptide-loading complex [45]. Stable 
assembly of the MHC class I peptide-loading complex is impaired without ERp57, leading to decreased surface expression of MHC class I peptides [46]. Cell surface MHC I expression is essential for the induction of immune responses [47] because MHC class I molecules are involved in antigen presentation and display peptides to circulating CD8+ cytotoxic T cells to enable tumor antigen recognition and induce $\mathrm{CD} 8+\mathrm{T}$ cell activation, eliciting antitumor immune responses and inducing cancer cell death [48]. If MHC class I surface expression is low, cancer cells fail to induce robust immune responses and exhibit weak immunogenicity [49], which is the major mechanism by which tumor cells escape immune attack [50]. Moreover, ERp57 expression is associated with CD8+ cytotoxic $\mathrm{T}$ lymphocyte dysfunction. The antitumor activity of $\mathrm{CD}^{+} \mathrm{T}$ cells is enhanced when ERp57 is knocked out in human CD8 ${ }^{+} \mathrm{T}$ cells because ERp57 knockout in $\mathrm{CD}^{+} \mathrm{T}$ cells regulates the expression of multiple immune regulators and effectors on the cell surface [51]. Hence, these reports suggest that ERp57 has a critical role in maintaining antitumor immune responses; thus, it may emerge as a potential cancer therapeutic target for the treatment of tumors for which prior treatment failed to induce strong $\mathrm{T}$ cell-mediated immune responses. The mechanism by which ERp57 regulates immune responses and the activity of $\mathrm{CD}^{+} \mathrm{T}$ cells need to be explored in detail to expand the utility of ERp57 in cancer immunotherapy strategies.

\section{Regulation of immunogenic cell death}

Immunogenic cell death (ICD), a type of regulated cell death (RCD), induces adaptive immune responses to kill cells directly $[52,53]$. CRT exposure on the cell surface triggers immune responses and facilitates recognition and removal of apoptotic cells [54, 55]. ER stress responses are required for ERp57/CRT exposure on the plasma membrane [56]. Knockdown of ERp57 simultaneously inhibits CRT translocation to the surface and exposure, preventing the restoration of tumor cell immunogenicity [57, 58]. Many studies have shown that radiation therapy and some chemotherapeutics, in particular anthracycline agents, can induce immune responses and lead to ICD $[52,59]$. ERp57-deficient cancer cells treated with anthracyclines are unable to elicit anticancer immune responses and become resistant to anthracycline chemotherapy in vivo because CRT translocation is inhibited and immunogenic cell death is abolished [58]. These studies demonstrate that ERp57 is indispensable for maintaining the immunogenicity of cancer cells and inducing ICD in chemotherapy-treated cells. ERp57 is likely to be a potential indicator of the efficacy of cancer immunotherapy.

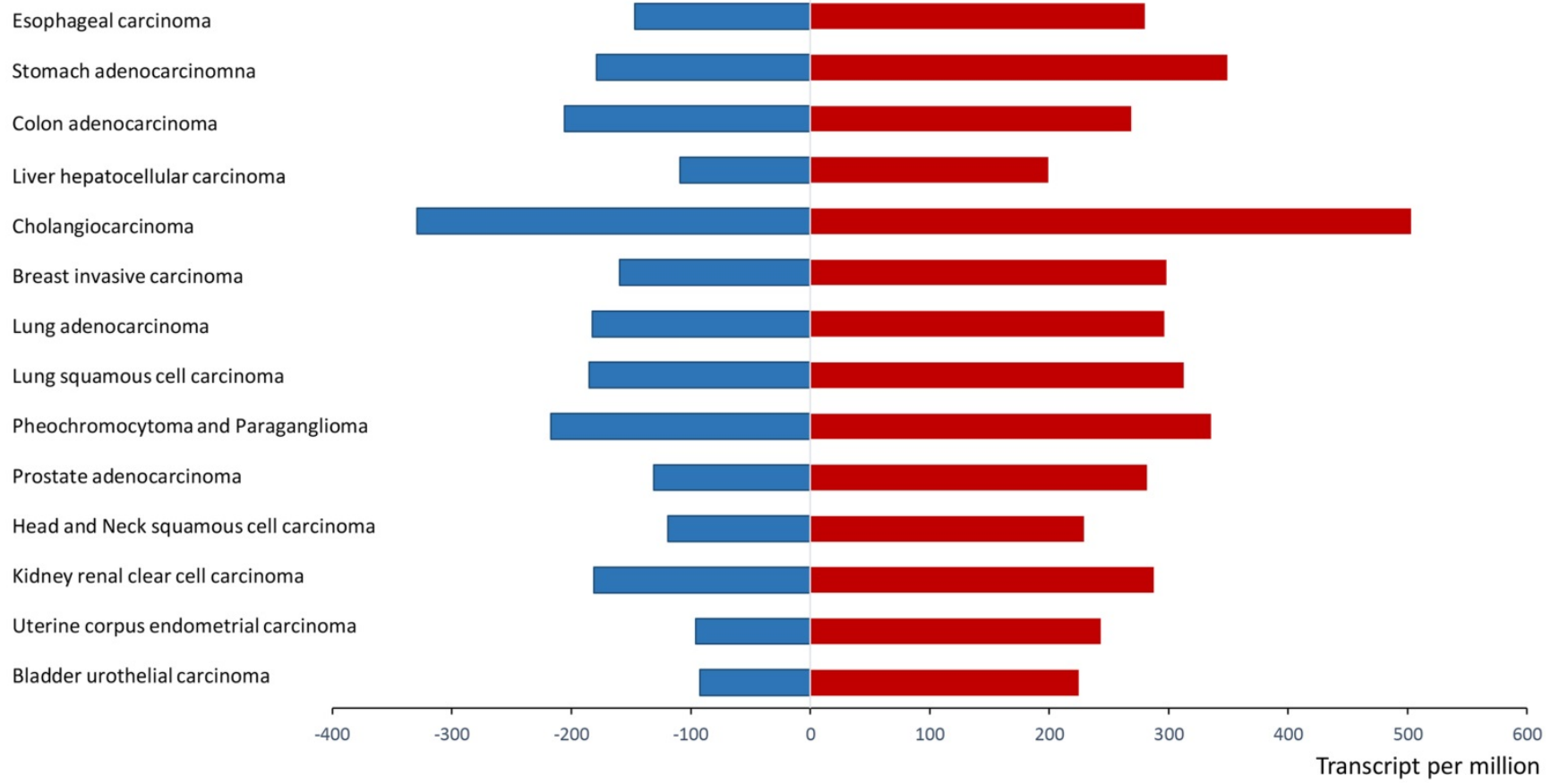

Figure 3. ERp57 expression in normal samples and tumor samples in the TCGA (UALCAN). ERp57 expression is significantly different between tumor samples and tumor samples $(P<0.05)$ according to TCGA genomics data for a wide variety of cancers. The difference in mRNA expression was assessed by Student's t-test. 


\section{Regulation of the UPR}

Due to its disulfide isomerase activity, ERp57 forms a complex with CNX and CRT to specifically modulate the folding of newly synthesized glycoproteins by facilitating the formation of native disulfide bonds [60, 61]. In response to intrinsic (oncogene activation) and extrinsic (hypoxia, chemicals or nutrient deficiency) stressors, unfolded and misfolded proteins accumulate in the ER lumen [62]. To ease the burden of the ER lumen, the UPR, a finely regulated program, is activated to maintain ER homeostasis and prevent ER stress from inducing death [63]. ERp57, as one of the key chaperones of the UPR, is required for this process. Knockdown of ERp57 enhances the ER stress response and facilitates the activation of ATF4/XBP-1 cascades [64]. Recent studies have provided evidence that ERp57 maintains the redox state of PDI and that knockdown of ERp57 facilitates PDI oxidation and activates PERK/CHOP cascades to induce p53-dependent apoptosis [65]. Moreover, the redox state of ERp57 is very significant. Evidence shows that the action of ERp57 is modulated by ROS because it can induce the oxidative modification of ERp57 and reverse the inhibitory effect on HCC progression [66]. In a breast cancer mammosphere model employing SUM159PT cells, mammosphere survival and growth were partially inhibited when ERp57 was knocked down because the effects of the ER protein folding machinery were decreased [67]. ER stress plays a critical role in tumor proliferation, progression and resistance, and the UPR alleviates cellular stress and promotes cell survival $[68,69]$. Recent progress has revealed that ERp57 regulates the UPR, providing valuable information for disrupting the chronic ER stress conditions of cancer. An increasing body of evidence indicates that the UPR may be a target for anticancer therapeutics [70]. Studies have reported that ERp57 may be a regulator of the UPR. However, the functional role of ERp57 in the modulation of the UPR in cancer depends on some elements, including the oxidative modification of ERp57, the tumor type, the ER stress conditions and other undetermined factors; thus, more research is required for a deeper understanding.

\section{Regulation of DNA repair signaling}

Recent data suggest that ERp57 plays an important role in the DNA repair process. ERp57, accompanied by high mobility group proteins 1 and 2 (HMGB1 and HMGB2), acts as a component of a complex that detects damaged DNA, inactivates the mismatch repair system and decreases the sensitivity of cells to thiopurine treatment [71, 72]. Inhibition of ERp57 significantly abrogates the phosphorylation of
H2Ax and suppresses the induction of the DNA damage response by cytarabine in A549 and UO31 human carcinoma cells [73]. Ref-1, a potent activator of p53 [74], can regulate p53-mediated base excision repair [75]. ERp57 interacts with Ref-1 through its thioredoxin-like domains and cooperates with it to regulate redox-sensitive transcription factor activation, ultimately yielding a protective effect against oxidative insult [76]. ERp57, vimentin and the nuclear proteins nucleophosmin (NPM1) and nucleolin (NCL) are major proteins exposed after cell injury; these proteins are necessary for the repair of plasma membrane damage and function as wound-associated proteins [77]. Vimentin can protect cells from DNA damage [78], and NPM1 and NCL are DNA damage proteins that directly participate in DNA repair $[79,80]$. ERp57 has been found to form a complex with vimentin [5], NPM1 and NCL to regulate cell division and cancer development [81]; however, the underlying mechanism has not been fully illustrated so far. In addition, ERp57 has roles in chromosome cohesion and segregation; it complexes with $\beta$-actin and III $\beta$-tubulin (TUBB3) in the nuclear compartment, participating in the regulation of actin conformation states [81] and the attachment of microtubules to chromosomes, which plays a key role in paclitaxel sensitivity [82].

Taken together, the evidence indicates that ERp57 has a protective effect on the survival of tumor cells due to its contribution to the DNA repair process, which regulates the sensitivity of the tumor to DNA-modifying chemotherapy. Thus, it may become a biomarker to predict therapeutic failure and success. However, further studies are required to confirm these findings and identify potential antitumor targets.

\section{Regulation of membrane-initiated signaling pathways}

$1,25(\mathrm{OH})_{2} \mathrm{D}_{3}$ is the active form of vitamin $\mathrm{D}$, and its analogs exert inhibitory effects on the proliferation and progression of multiple cancers, including melanoma [83], prostate cancer, and leukemia [83, 84]. ERp57 acts as a 1,25D 3 -membrane-associated, rapid response to steroid binding $\left(1,25 \mathrm{D}_{3}\right.$-MARRS) receptor, mainly located on the plasma membrane and Golgi/ER [85-87]. It binds to secosteroid 1,25(OH $)_{2} \mathrm{D}_{3}$ to form a ligand-receptor complex to mediate several rapid signal transduction cascades; for example, it regulates STAT3 [88] and the NF-kB pathway [89], promotes the formation of complexes involving ERp57 and other proteins, and translocates to the nucleus to regulate gene expression [27]. ERp57 complexes with NF-KB to activate downstream cascades to regulate leukemia cell differentiation [89]. 
ERp57 regulates the transcription and translation of STAT3 through binding to STAT3 DNA and protein [90] and regulates the level of STAT3 phosphorylation to modulate the transcriptional activity of STAT3, which affects gene expression [91, 92]. The ERp57/STAT3 complex translocates to the nucleus to induce MCOLN3 expression and enhance $\mathrm{Ca}^{2+}$ release from lysosomes to activate autolysosomal degradation [93]. In vitro studies have revealed that knockdown of ERp57 inhibits HCC cell proliferation [92] and enhances the paclitaxel sensitivity of paclitaxel-resistant SKOV3/tax cells by blocking the STAT3 pathway [5]. Furthermore, a study reported that knockdown of ERp57 prevents EGFR-mediated cancer proliferation by inhibiting the internalization and phosphorylation of the EGF receptor [94]. EGFR amplification or mutation facilitates tumor proliferation, invasion, migration and apoptosis inhibition by regulating multiple downstream cascades, and EGFR inhibitors provide an effective therapeutic target for EGFR-mediated cancer [95]. Thus, analysis of the inhibitory function of ERp57 on EGFR-mediated cancer could open a new avenue to further explore optimized treatment options.

\section{Regulation of other signal transduction pathways}

Mitomycin C (MMC) exerts anticancer effects by inducing DNA cross-linking in cancer cells [96]. ERp57 functions as a reductase, catalyzes the metabolic reduction of MMC and induces DNA cross-linking via its two thioredoxin-like domains [97], leading to increased MMC cytotoxicity [96]. MMC cytotoxicity induced by DNA cross-linking and breakage is also associated with numerous side effects, such as lack of appetite, weight loss, and renal toxicity, which are alleviated after inhibition of ERp57 [98].

Affymetrix microarray results suggest that cytoskeletal remodeling and the Wnt signaling pathway are the two of the top pathways disrupted by ERp57 silencing in HeLa cells [99]. The present data demonstrate that $\beta$-catenin participates in the mechanisms of cell adhesion, cytoskeleton remodeling and the canonical Wnt signaling pathway [100]. Stable knockdown of ERp57 induces $\beta$-catenin accumulation and inhibits the migration of HeLa cells [99], and resveratrol can increase the interaction between ERp57 and $\beta$-catenin [101]. In addition, ERp57 can regulate the proliferation, invasion and migration of cancer via the MAPK signaling pathway. Downregulation of ERp57 suppresses JNK, ERK and p38 phosphorylation [102], ERp57 expression requires ERK and p38, and inhibition of the ERK/p38 MARK pathway suppresses ERp57 expression [98]. Little is known regarding the regulatory role of ERp57 in these pathways, and more research is needed to confirm these findings.

\section{Conclusions}

ERp57 plays an important role in the natural history of cancer and the therapeutic process. As an ER chaperone, ERp57 is associated with CRT and CNX, participates in MHC class I molecule assembly $[103,104]$, regulates tumor cell immunogenicity [105], facilitates new glycoprotein synthesis and enhances oxidative refolding of denatured cells [106], functions as a $1,25 \mathrm{D}_{3}$-MARRS receptor [107], regulates gene transcription, binds to STAT3 and NF- $\mathrm{KB}$, enhances MMC-induced DNA cross-linking and is involved in DNA repair processes and cytoskeletal remodeling (Figure 4). Numerous studies have demonstrated that ERp57 plays a significant role in tumor development and chemoresistance in a wide variety of cancers. These identified crucial roles and their regulatory pathways may provide a framework for the comprehensive understanding of ERp57 in cancer, which might indicate its potential as a potential therapeutic target for cancer treatment.

\section{Abbreviations}

ERp57: Endoplasmic reticulum resident protein 57; PDIA3: protein disulfide-isomerase A3; PDI: protein disulfide-isomerase; ER: endoplasmic reticulum; MHC: major histocompatibility complex; ICD: immunogenic cell death; UPR: unfolded protein response; $1,25(\mathrm{OH})_{2} \mathrm{D}_{3}$ : 1,25-dihydroxy vitamin $\mathrm{D}_{3}$; GRP58: glucose regulatory protein 58; CGHC: Cys-Gly-His-Cys; QEDL: Gln-Glu-Asp-Leu; HCC: hepatocellular carcinoma; TCGA: The Cancer Genome Atlas; CNX: calnexin; CRT: calreticulin; CST: castanospermine; RCD: regulated cell death; HMGB1: high mobility group proteins 1; HMGB2: high mobility group proteins 2; NPMI: nucleophosmin; NCL: nucleolin; TUBB3: III $\beta$-tubulin; $1,25 \mathrm{D}_{3}$-MARRS: $1,25 \mathrm{D}_{3}$-membrane-associated, rapid response to steroid binding; MMC: Mitomycin C.

\section{Acknowledgments}

Our work was funded by fundamental research funds for the National Center for Clinical Medicine of Digestive Diseases (No. 2015BAI13B07, to Daiming Fan), the Natural Science Foundation of China (No. 81430072, to Daiming Fan), and the Scientific Fund for Innovative Research Groups of the National Natural Science Foundation of China (No. 81421003, to Daiming Fan). 


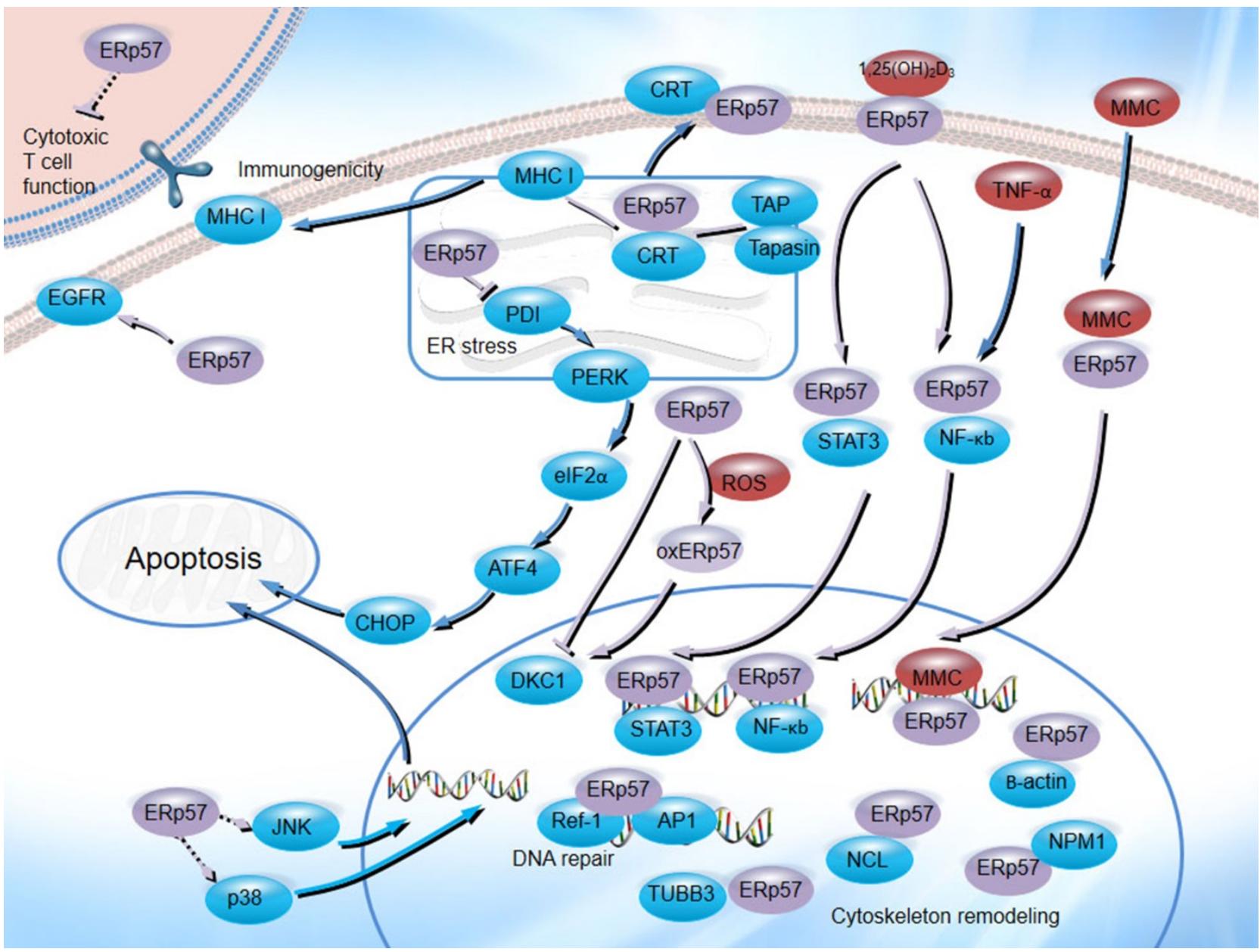

Figure 4. The biological functions of ERp57 in cancer. ERp57 regulates diverse signal transduction pathways: ERp57 is associated with CRT and CNX, participates in MHC class I molecule assembly, inhibits T cell-mediated immune responses, regulates the UPR, functions as a receptor for $1,25(\mathrm{OH})_{2} \mathrm{D}_{3}$, binds to STAT3 and NF-KB, enhances MMC-induced DNA cross-linking, and participates in DNA repair processes and cytoskeletal remodeling.

\section{Competing Interests}

The authors have declared that no competing interest exists.

\section{References}

1. Bray F, Ferlay J, Soerjomataram I, Siegel RL, Torre LA, Jemal A. Global cancer statistics 2018: GLOBOCAN estimates of incidence and mortality worldwide for 36 cancers in 185 countries. CA: a cancer journal for clinicians. 2018; 68: 394-424

2. Maresso KC, Tsai KY, Brown PH, Szabo E, Lippman S, Hawk ET. Molecular cancer prevention: Current status and future directions. CA: a cancer journal for clinicians. 2015; 65: 345-83.

3. Park S, Park JH, Jung HJ, Jang JH, Ahn S, Kim Y, et al. A secretome profile indicative of oleate-induced proliferation of HepG2 hepatocellular carcinoma cells. Experimental \& molecular medicine. 2018; 50: 93.

4. Chen Y, Lin MC, Wang H, Chan CY, Jiang L, Ngai SM, et al. Proteomic analysis of EZH2 downstream target proteins in hepatocellular carcinoma. Proteomics. 2007; 7: 3097-104.

5. Li S, Zhao X, Chang S, Li Y, Guo M, Guan Y. ERp57small interfering RNA silencing can enhance the sensitivity of drugresistant human ovarian cancer cells to paclitaxel. International journal of oncology. 2019; 54: 249-60.

6. Chignard N, Shang S, Wang H, Marrero J, Brechot C, Hanash S, et al. Cleavage of endoplasmic reticulum proteins in hepatocellular carcinoma: Detection of generated fragments in patient sera. Gastroenterology. 2006; 130: 2010-22.

7. Hirano N, Shibasaki F, Sakai R, Tanaka T, Nishida J, Yazaki Y, et al. Molecular cloning of the human glucose-regulated protein ERp57/GRP58, a thiol-dependent reductase. Identification of its secretory form and inducible expression by the oncogenic transformation. European journal of biochemistry. 1995; 234: 336-42.
8. Turano C, Coppari S, Altieri F, Ferraro A. Proteins of the PDI family: unpredicted non-ER locations and functions. Journal of cellular physiology. 2002; 193: 154-63.

9. Tohda C, Urano T, Umezaki M, Nemere I, Kuboyama T. Diosgenin is an exogenous activator of 1,25D(3)-MARRS/Pdia3/ERp57 and improves Alzheimer's disease pathologies in 5XFAD mice. Scientific reports. 2012; 2: 535.

10. Vitello AM, Du Y, Buttrick PM, Walker LA. Serendipitous discovery of a novel protein signaling mechanism in heart failure. Biochemical and biophysical research communications. 2012; 421: 431-5.

11. Wu Y, Ahmad SS, Zhou J, Wang L, Cully MP, Essex DW. The disulfide isomerase ERp57 mediates platelet aggregation, hemostasis, and thrombosis. Blood. 2012; 119: 1737-46.

12. Furie B, Flaumenhaft R. Thiol isomerases in thrombus formation. Circulation research. 2014; 114: 1162-73.

13. Hettinghouse A, Liu R, Liu CJ. Multifunctional molecule ERp57: From cancer to neurodegenerative diseases. Pharmacology \& therapeutics. 2018; 181: 34-48.

14. Okumura M, Kadokura H, Inaba K. Structures and functions of protein disulfide isomerase family members involved in proteostasis in the endoplasmic reticulum. Free radical biology \& medicine. 2015; 83: 314-22.

15. Lee E, Lee DH. Emerging roles of protein disulfide isomerase in cancer. BMB reports. 2017; 50: 401-10.

16. Ellgaard L, Ruddock LW. The human protein disulphide isomerase family: substrate interactions and functional properties. EMBO reports. 2005; 6: 28-32.

17. Frickel EM, Frei P, Bouvier M, Stafford WF, Helenius A, Glockshuber R, et al. ERp57 is a multifunctional thiol-disulfide oxidoreductase. The Journal of biological chemistry. 2004; 279: 18277-87.

18. Byrne LJ, Sidhu A, Wallis AK, Ruddock LW, Freedman RB, Howard MJ, et al. Mapping of the ligand-binding site on the $b^{\prime}$ domain of human PDI: interaction with peptide ligands and the x-linker region. The Biochemical journal. 2009; 423: 209-17.

19. Mazzarella RA, Marcus N, Haugejorden SM, Balcarek JM, Baldassare JJ, Roy B, et al. Erp61 is GRP58, a stress-inducible luminal endoplasmic reticulum protein, but is devoid of phosphatidylinositide-specific phospholipase C activity. Archives of biochemistry and biophysics. 1994; 308: 454-60. 
20. Urade $\mathrm{R}$, Oda $\mathrm{T}$, Ito $\mathrm{H}$, Moriyama $\mathrm{T}$, Utsumi $\mathrm{S}$, Kito $\mathrm{M}$. Functions of characteristic Cys-Gly-His-Cys (CGHC) and Gln-Glu-Asp-Leu (QEDL) motifs of microsomal ER-60 protease. Journal of biochemistry. 1997; 122: 834-42.

21. Otsu M, Urade R, Kito M, Omura F, Kikuchi M. A possible role of ER-60 protease in the degradation of misfolded proteins in the endoplasmic reticulum. The Journal of biological chemistry. 1995; 270: 14958-61.

22. Coppari S, Altieri F, Ferraro A, Chichiarelli S, Eufemi M, Turano C. Nuclear localization and DNA interaction of protein disulfide isomerase ERp57 in mammalian cells. Journal of cellular biochemistry. 2002; 85: 325-33.

23. Grillo C, D'Ambrosio C, Consalvi V, Chiaraluce R, Scaloni A, Maceroni M, et al. DNA-binding activity of the ERp57 C-terminal domain is related to a redox-dependent conformational change. The Journal of biological chemistry. 2007; 282: 10299-310.

24. Grillo C, Coppari S, Turano C, Altieri F. The DNA-binding activity of protein disulfide isomerase ERp57 is associated with the a(') domain. Biochemical and biophysical research communications. 2002; 295: 67-73.

25. Ferraro A, Altieri F, Coppari S, Eufemi M, Chichiarelli S, Turano C. Binding of the protein disulfide isomerase isoform ERp60 to the nuclear matrix-associated regions of DNA. Journal of cellular biochemistry. 1999; 72: 528-39.

26. Shaffer KL, Sharma A, Snapp EL, Hegde RS. Regulation of protein compartmentalization expands the diversity of protein function. Developmental cell. 2005; 9: 545-54.

27. Grindel BJ, Rohe B, Safford SE, Bennett JJ, Farach-Carson MC. Tumor necrosis factor-alpha treatment of HepG2 cells mobilizes a cytoplasmic pool of ERp57/1,25D(3)-MARRS to the nucleus. Journal of cellular biochemistry. 2011; 112: 2606-15.

28. Chandrashekar DS, Bashel B, Balasubramanya SAH, Creighton CI, Ponce-Rodriguez I, Chakravarthi B, et al. UALCAN: A Portal for Facilitating Tumor Subgroup Gene Expression and Survival Analyses.

29. Cheng K, Lee JS, Hao P, Yao SQ Ding K, Li Z Tetrazole-Based Probes for Integrated Phenotypic Screening, Affinity-Based Proteome Profiling, and Sensitive Detection of a Cancer Biomarker. Angewandte Chemie (International ed in English). 2017; 56: 15044-8.

30. Yang Z, Liu J, Shi Q, Chao Y, Di Y, Sun J, et al. Expression of protein disulfide isomerase A3 precursor in colorectal cancer. OncoTargets and therapy. 2018; 11: 4159-66.

31. Da Costa GG, Gomig TH, Kaviski R, Santos Sousa K, Kukolj C, De Lima RS, et al. Comparative Proteomics of Tumor and Paired Normal Breast Tissue Highlights Potential Biomarkers in Breast Cancer. Cancer genomics \& proteomics. 2015; 12: 251-61.

32. Ramos FS, Serino LT, Carvalho CM, Lima RS, Urban CA, Cavalli IJ, et al. PDIA3 and PDIA6 gene expression as an aggressiveness marker in primary ductal breast cancer. Genetics and molecular research : GMR. 2015; 14: 6960-7.

33. Liao CJ, Wu TI, Huang $\mathrm{YH}$, Chang TC, Wang CS, Tsai MM, et al. Glucose-regulated protein 58 modulates cell invasiveness and serves as a prognostic marker for cervical cancer. Cancer science. 2011; 102: 2255-63.

34. Chay D, Cho H, Lim BJ, Kang ES, Oh YJ, Choi SM, et al. ER-60 (PDIA3) is highly expressed in a newly established serous ovarian cancer cell line, YDOV-139. International journal of oncology. 2010; 37: 399-412.

35. Pressinotti NC, Klocker H, Schafer G, Luu VD, Ruschhaupt M, Kuner R, et al. Differential expression of apoptotic genes PDIA3 and MAP3K5 distinguishes between low- and high-risk prostate cancer. Molecular cancer. 2009; 8: 130.

36. Linge A, Kennedy S, O'Flynn D, Beatty S, Moriarty P, Henry M, et al. Differential expression of fourteen proteins between uveal melanoma from patients who subsequently developed distant metastases versus those who did Not. Investigative ophthalmology \& visual science. 2012; 53: 4634-43.

37. Leys CM, Nomura S, LaFleur BJ, Ferrone S, Kaminishi M, Montgomery E, et al. Expression and prognostic significance of prothymosin-alpha and ERp57 in human gastric cancer. Surgery. 2007; 141: 41-50.

38. Shimoda T, Wada R, Kure S, Ishino K, Kudo M, Ohashi R, et al. Expression of protein disulfide isomerase A3 and its clinicopathological association in gastric cancer. Oncology reports. 2019; 41: 2265-72.

39. Ren H, Du N, Liu G, Hu HT, Tian W, Deng ZP, et al. Analysis of variabilities of serum proteomic spectra in patients with gastric cancer before and after operation. World journal of gastroenterology. 2006; 12: 2789-92.

40. Oliver JD, van der Wal FJ, Bulleid NJ, High S. anti-tumor activity. Science (New York, NY). 1997; 275: 86-8.

41. Oliver JD, Roderick HL, Llewellyn DH, High S. ERp57 functions as a subunit of specific complexes formed with the ER lectins calreticulin and calnexin. Molecular biology of the cell. 1999; 10: 2573-82.

42. Molinari M, Helenius A. Glycoproteins form mixed disulphides with oxidoreductases during folding in living cells. Nature. 1999; 402: 90-3.

43. Lindquist JA, Jensen ON, Mann M, Hammerling GJ. ER-60, a chaperone with thiol-dependent reductase activity involved in MHC class I assembly. The EMBO journal. 1998; 17: 2186-95.

44. Coe H, Michalak M. ERp57, a multifunctional endoplasmic reticulum resident oxidoreductase. The international journal of biochemistry \& cell biology. 2010; 42: 796-9.

45. Androlewicz MJ. The role of tapasin in MHC class I antigen assembly. Immunologic research. 1999; 20: 79-88.

46. Garbi N, Tanaka S, Momburg F, Hammerling GJ. Impaired assembly of the major histocompatibility complex class I peptide-loading complex in mice deficient in the oxidoreductase ERp57. Nature immunology. 2006; 7: 93-102.
47. Reeves E, James E. Tumour and placenta establishment: The importance of antigen processing and presentation.

48. Reeves E, James E. Antigen processing and immune regulation in the response to tumours.

49. Seliger B, Wollscheid U, Momburg F, Blankenstein T, Huber C. Characterization of the major histocompatibility complex class I deficiencies in B16 melanoma cells. Cancer research. 2001; 61: 1095-9.

50. Garrido F, Aptsiauri N. Cancer immune escape: MHC expression in primary tumours versus metastases.

51. Ye L, Park JJ, Dong MB, Yang Q, Chow RD, Peng L, et al. In vivo CRISPR screening in CD8 T cells with AAV-Sleeping Beauty hybrid vectors identifies membrane targets for improving immunotherapy for glioblastoma. Nature biotechnology. 2019; 37: 1302-13.

52. Fumet JD, Limagne E, Thibaudin M, Ghiringhelli FA-O. Immunogenic Cell Death and Elimination of Immunosuppressive Cells: A Double-Edged Sword of Chemotherapy. LID - E2637 [pii] LID - 10.3390/cancers12092637 [doi].

53. Zhou J, Wang GA-O, Chen Y, Wang H, Hua Y, Cai Z. Immunogenic cell death in cancer therapy: Present and emerging inducers.

54. Obeid M, Tesniere A Fau - Ghiringhelli F, Ghiringhelli F Fau - Fimia GM, Fimia Gm Fau - Apetoh L, Apetoh L Fau - Perfettini J-L, Perfettini Jl Fau Castedo M, et al. Calreticulin exposure dictates the immunogenicity of cancer cell death.

55. Zamanian M, Veerakumarasivam A Fau - Abdullah S, Abdullah S Fau - Rosli R, Rosli R. Calreticulin and cancer.

56. Panaretakis T, Kepp O, Brockmeier U, Tesniere A, Bjorklund AC, Chapman DC, et al. Mechanisms of pre-apoptotic calreticulin exposure in immunogenic cell death. The EMBO journal. 2009; 28: 578-90.

57. Obeid M. ERP57 membrane translocation dictates the immunogenicity of tumor cell death by controlling the membrane translocation of calreticulin. Journal of immunology (Baltimore, Md : 1950). 2008; 181: 2533-43.

58. Panaretakis T, Joza N, Modjtahedi N, Tesniere A, Vitale I, Durchschlag M, et al. The co-translocation of ERp57 and calreticulin determines the immunogenicity of cell death. Cell death and differentiation. 2008; 15: 1499-509.

59. Zitvogel L, Apetoh L Fau - Ghiringhelli F, Ghiringhelli F Fau - André F, André F Fau - Tesniere A, Tesniere A Fau - Kroemer G, Kroemer G. The anticancer immune response: indispensable for therapeutic success?

60. Oliver JD, van der Wal Fj Fau - Bulleid NJ, Bulleid Nj Fau - High S, High S. Interaction of the thiol-dependent reductase ERp57 with nascent glycoproteins.

61. High S, Lecomte Fj Fau - Russell SJ, Russell Sj Fau - Abell BM, Abell Bm Fau Oliver JD, Oliver JD. Glycoprotein folding in the endoplasmic reticulum: a tale of three chaperones?

62. Walter P, Ron D. The unfolded protein response: from stress pathway to homeostatic regulation. Science (New York, NY). 2011; 334: 1081-6.

63. Ron D, Walter P. Signal integration in the endoplasmic reticulum unfolded protein response. Nature reviews Molecular cell biology. 2007; 8: 519-29.

64. Corazzari M, Lovat PE, Armstrong JL, Fimia GM, Hill DS, Birch-Machin M, et al. Targeting homeostatic mechanisms of endoplasmic reticulum stress to increase susceptibility of cancer cells to fenretinide-induced apoptosis: the role of stress proteins ERdj5 and ERp57. British journal of cancer. 2007; 96: 1062-71.

65. Kranz P, Neumann F, Wolf A, Classen F, Pompsch M, Ocklenburg T, et al. PDI is an essential redox-sensitive activator of PERK during the unfolded protein response (UPR). Cell death \& disease. 2017; 8: e2986.

66. Ko E, Kim JS, Ju S, Seo HW, Chang Y, Kang JA, et al. Oxidatively Modified Protein-Disulfide Isomerase-Associated 3 Promotes Dyskerin Pseudouridine Synthase 1-Mediated Malignancy and Survival of Hepatocellular Carcinoma Cells. Hepatology (Baltimore, Md). 2018; 68: 1851-64.

67. Wise R, Duhachek-Muggy S, Oi Y, Zolkiewski M, Zolkiewska A. Protein disulfide isomerases in the endoplasmic reticulum promote anchorage-independent growth of breast cancer cells. Breast cancer research and treatment. 2016; 157: 241-52.

68. O'Malley J, Kumar R, Inigo J, Yadava N, Chandra D. Mitochondrial Stress Response and Cancer.

69. Hetz CA-O, Zhang KA-OX, Kaufman RA-OX. Mechanisms, regulation and functions of the unfolded protein response.

70. Wang M, Law ME, Castellano RK, Law BK. The unfolded protein response as a target for anticancer therapeutics.

71. Chichiarelli S, Ferraro A, Altieri F, Eufemi M, Coppari S, Grillo C, et al. The stress protein ERp57/GRP58 binds specific DNA sequences in HeLa cells. Journal of cellular physiology. 2007; 210: 343-51.

72. Krynetski EY, Krynetskaia Nf Fau - Bianchi ME, Bianchi Me Fau - Evans WE, Evans WE. A nuclear protein complex containing high mobility group proteins B1 and B2, heat shock cognate protein 70, ERp60, and glyceraldehyde-3-phosphate dehydrogenase is involved in the cytotoxic response to DNA modified by incorporation of anticancer nucleoside analogues.

73. Krynetskaia NF, Phadke MS, Jadhav SH, Krynetskiy EY. Chromatin-associated proteins HMGB1/2 and PDIA3 trigger cellular response to chemotherapy-induced DNA damage. Molecular cancer therapeutics. 2009; 8: $864-72$

74. Jayaraman L, Murthy Kg Fau - Zhu C, Zhu C Fau - Curran T, Curran T Fau Xanthoudakis S, Xanthoudakis S Fau - Prives C, Prives C. Identification of redox/repair protein Ref- 1 as a potent activator of $\mathrm{p} 53$. 
75. Jung HJ, Kim Hl Fau - Kim YJ, Kim Yj Fau - Weon J-I, Weon Ji Fau - Seo YR, Seo YR. A novel chemopreventive mechanism of selenomethionine: enhancement of APE1 enzyme activity via a Gadd45a, PCNA and APE1 protein complex that regulates $\mathrm{p} 53$-mediated base excision repair.

76. Grillo C, D'Ambrosio C, Scaloni A, Maceroni M, Merluzzi S, Turano C, et al. Cooperative activity of Ref-1/APE and ERp57 in reductive activation of transcription factors. Free radical biology \& medicine. 2006; 41: 1113-23.

77. Mellgren RL. A plasma membrane wound proteome: reversible externalization of intracellular proteins following reparable mechanical damage. The Journal of biological chemistry. 2010; 285: 36597-607.

78. Patteson AE, Vahabikashi A, Pogoda K, Adam SA, Mandal K, Kittisopikul M, et al. Vimentin protects cells against nuclear rupture and DNA damage during migration. The Journal of cell biology. 2019; 218: 4079-92.

79. Yang C, Maiguel DA, Carrier F. Identification of nucleolin and nucleophosmin as genotoxic stress-responsive RNA-binding proteins. Nucleic acids research. 2002; 30: 2251-60.

80. Scott DD, Oeffinger M. Nucleolin and nucleophosmin: nucleolar proteins with multiple functions in DNA repair. Biochemistry and cell biology $=$ Biochimie et biologie cellulaire. 2016; 94: 419-32.

81. Cicchillitti L, Della Corte A, Di Michele M, Donati MB, Rotilio D, Scambia G. Characterisation of a multimeric protein complex associated with ERp57 within the nucleus in paclitaxel-sensitive and -resistant epithelial ovarian cancer cells: the involvement of specific conformational states of beta-actin. International journal of oncology. 2010; 37: 445-54.

82. Cicchillitti L, Di Michele M, Urbani A, Ferlini C, Donat MB, Scambia G, et al. Comparative proteomic analysis of paclitaxel sensitive A2780 epithelial ovarian cancer cell line and its resistant counterpart A2780TC1 by 2D-DIGE: the role of ERp57. Journal of proteome research. 2009; 8: 1902-12.

83. Szyszka P, Zmijewski MA, Slominski AT. New vitamin D analogs as potential therapeutics in melanoma. Expert review of anticancer therapy. 2012; 12: 585-99.

84. Feldman D, Krishnan AV, Swami S, Giovannucci E, Feldman BJ. The role of vitamin $\mathrm{D}$ in reducing cancer risk and progression. Nature reviews Cancer. 2014; 14: 342-57.

85. Farach-Carson MC, Nemere I. Membrane receptors for vitamin D steroid hormones: potential new drug targets. Current drug targets. 2003; 4: 67-76.

86. Nemere I, Safford SE, Rohe B, DeSouza MM, Farach-Carson MC. Identification and characterization of 1,25D3-membrane-associated rapid response, steroid (1,25D3-MARRS) binding protein. The Journal of steroid biochemistry and molecular biology. 2004; 89-90: 281-5.

87. Nemere I, Ray R, McManus W. Immunochemical studies on the putative plasmalemmal receptor for $1,25(\mathrm{OH})(2) \mathrm{D}(3)$. I. Chick intestine. American journal of physiology Endocrinology and metabolism. 2000; 278: E1104-14.

88. Karlsson S, Olausson J, Lundh D, Sogard P, Mandal A, Holmstrom KO, et al. Vitamin D and prostate cancer: the role of membrane initiated signaling pathways in prostate cancer progression. The Journal of steroid biochemistry and molecular biology. 2010; 121: 413-6.

89. Wu W, Beilhartz G, Roy $\mathrm{Y}$, Richard CL, Curtin M, Brown L, et al. Nuclear translocation of the 1,25D3-MARRS (membrane associated rapid response to steroids) receptor protein and NFkappaB in differentiating NB4 leukemia cells. Experimental cell research. 2010; 316: 1101-8.

90. Liu Y, Wang JX, Nie ZY, Wen Y, Jia XJ, Zhang LN, et al. Upregulation of ERp57 promotes clear cell renal cell carcinoma progression by initiating a STAT3/ILF3 feedback loop. Journal of experimental \& clinical cancer research : CR. 2019; 38: 439.

91. Chichiarelli S, Gaucci E, Ferraro A, Grillo C, Altieri F, Cocchiola R, et al. Role of ERp57 in the signaling and transcriptional activity of STAT3 in a melanoma cell line. Archives of biochemistry and biophysics. 2010; 494: 178-83.

92. Kondo $\mathrm{R}$, Ishino $\mathrm{K}$, Wada $\mathrm{R}$, Takata $\mathrm{H}$, Peng $\mathrm{WX}$, Kudo $\mathrm{M}$, et al. Downregulation of protein disulfideisomerase A3 expression inhibits cell proliferation and induces apoptosis through STAT3 signaling in hepatocellular carcinoma. International journal of oncology. 2019; 54: 1409-21.

93. Hu W, Zhang L, Li MX, Shen J, Liu XD, Xiao ZG, et al. Vitamin D3 activates the autolysosomal degradation function against Helicobacter pylori through the PDIA3 receptor in gastric epithelial cells. Autophagy. 2019; 15: 707-25.

94. Gaucci E, Altieri F, Turano C, Chichiarelli S. The protein ERp57 contributes to EGF receptor signaling and internalization in MDA-MB-468 breast cancer cells. Journal of cellular biochemistry. 2013; 114: 2461-70.

95. Frawley T, Piskareva OA-O. Extracellular Vesicle Dissemination of Epidermal Growth Factor Receptor and Ligands and Its Role in Cancer Progression. LID E3200 [pii] LID - 10.3390/cancers12113200 [doi].

96. Celli CM, Jaiswal AK. Role of GRP58 in mitomycin C-induced DNA cross-linking. Cancer research. 2003; 63: 6016-25.

97. Adikesavan AK, Jaiswal AK. Thioredoxin-like domains required for glucose regulatory protein 58 mediated reductive activation of mitomycin $C$ leading to DNA cross-linking. Molecular cancer therapeutics. 2007; 6: 2719-27.

98. Zhou QM, Zhang H, Lu YY, Wang XF, Su SB. Curcumin reduced the side effects of mitomycin C by inhibiting GRP58-mediated DNA cross-linking in MCF-7 breast cancer xenografts. Cancer science. 2009; 100: 2040-5.

99. Liao $\mathrm{CJ}, \mathrm{Wu} \mathrm{TI}$, Huang $\mathrm{YH}$, Chang $\mathrm{TC}$, Lai $\mathrm{CH}$, Jung $\mathrm{SM}$, et al. Glucose-regulated protein 58 modulates beta-catenin protein stability in a cervical adenocarcinoma cell line. BMC cancer. 2014; 14: 555.

100. Zhang $X$, Zhang $C$, Ren $Z$, Zhang FA-O, Xu J, Zhang X, et al. Curcumin Affects Gastric Cancer Cell Migration, Invasion and Cytoskeletal Remodeling Through Gli1- $\beta$-Catenin.
101. Menoret A, Drew DA, Miyamoto S, Nakanishi M, Vella AT, Rosenberg DW. Differential proteomics identifies PDIA3 as a novel chemoprevention target in human colon cancer cells. Molecular carcinogenesis. 2014; 53 Suppl 1: E11-22.

102. Ye Q, Fu P, Dou J, Wang N. Downregulation of PDIA3 inhibits proliferation and invasion of human acute myeloid leukemia cells. OncoTargets and therapy. 2018; 11: 2925-35.

103. Blees A, Januliene D, Hofmann T, Koller N, Schmidt C, Trowitzsch S, et al. Structure of the human MHC-I peptide-loading complex. Nature. 2017; 551: $525-8$

104. Dick TB. Assembly of MHC class I peptide complexes from the perspective of disulfide bond formation. Cellular and molecular life sciences: CMLS. 2004; 61: 547-56.

105. Liu CC, Leclair P, Pedari F, Vieira H, Monajemi M, Sly LM, et al. Integrins and ERp57 Coordinate to Regulate Cell Surface Calreticulin in Immunogenic Cell Death. Frontiers in oncology. 2019; 9: 411.

106. Okudo H, Kato H, Arakaki Y, Urade R. Cooperation of ER-60 and BiP in the oxidative refolding of denatured proteins in vitro. Journal of biochemistry. 2005; 138: 773-80.

107. Khanal RC, Nemere I. The ERp57/GRp58/1,25D3-MARRS receptor: multiple functional roles in diverse cell systems. Current medicinal chemistry. 2007; 14: 1087-93. 